\title{
Spontaneous dissection of the celiac trunk: report of three cases and review of the literature
}

\section{Dissecção espontânea do tronco celíaco: relato de três casos e revisão de literatura}

Ernesto Lima Araujo Melo', Rainne André Siqueira', Francisco Thiago Martins de Paula

\begin{abstract}
Spontaneous dissection of the celiac trunk is quite an uncommon medical condition, with few case reports in the medical literature. Sudden epigastric abdominal pain is the most common complaint reported by patients, but due to the rarity of this disease in clinical practice and the nonspecific nature of its symptoms, a high degree of clinical suspicion is needed to establish diagnosis. However, improvements in imaging techniques are facilitating diagnosis of this clinical entity, increasing its detection rate. The ideal treatment has not yet been fully established in the literature and the available therapeutic strategies are conservative medical treatment, surgical revascularization or endovascular intervention. In this article we report on three cases of spontaneous dissection of the celiac trunk and conduct a review of the literature on this disease
\end{abstract}

Keywords: dissection; acute pain; celiac artery.

\section{Resumo}

A dissecção espontânea do tronco celíaco é uma condição médica incomum, com poucos relatos de casos publicados na literatura médica. A dor abdominal súbita no epigástrio é o sintoma mais frequentemente manifestado pelos pacientes; porém, devido à raridade dessa doença na prática clínica eà inespecificidade de seus sintomas, é necessário um alto grau de suspeição para o estabelecimento do seu diagnóstico. Nesse contexto, o aperfeiçoamento das técnicas de exames de imagem vem possibilitando o diagnóstico desta entidade clínica com maior facilidade, aumentando a sua taxa de detecção. O tratamento ideal ainda não está completamente bem estabelecido na literatura, sendo que as estratégias terapêuticas disponíveis são o tratamento médico conservador, a revascularização cirúrgica e a intervenção endovascular. Neste artigo, nós relatamos três casos de dissecção espontânea do tronco celíaco e realizamos uma revisão de literatura sobre esta doença.

Palavras-chave: dissecção; dor aguda; artéria celíaca. 


\section{INTRODUCTION}

Spontaneous dissection of visceral arteries is a rare event, affecting the superior mesenteric artery and sometimes the celiac trunk, the splenic artery and the inferior mesenteric artery. ${ }^{1}$ Although the condition is rare, its incidence may have been underestimated in the past and it has historically been associated with poor prognosis. The exact cause of spontaneous dissection of visceral arteries is unknown, but arterial hypertension has classically been considered a predisposing factor. ${ }^{2-5}$ Abdominal pains are the most common symptom in people who have suffered spontaneous dissection of the celiac trunk, but patients may also exhibit nonspecific symptoms such as weight loss. ${ }^{1,5}$ As imaging methods have continually improved, diagnosis of this condition has been facilitated and it should be taken into account during differential diagnosis of epigastric abdominal pain. ${ }^{1,4}$ In view of the rarity of the condition, the ideal therapeutic management for dissection of the celiac trunk remains controversial. ${ }^{1-5}$ There are three possible treatment options available: conservative clinical treatment, surgical revascularization or endovascular treatment. ${ }^{1}$ The objective of this article is to describe three cases of spontaneous dissection of the celiac trunk and to conduct a review of the current literature on the subject.

\section{CASE REPORTS}

\section{Case 1}

FGS, a 52-year-old male patient with poorly controlled chronic systemic arterial hypertension, presented with sudden epigastric pain and nausea with onset 24 hours previously. Abdominal ultrasonography findings were normal, but angiotomographic investigation identified a dissection flap in the celiac trunk (Figure 1). The condition was treated clinically and the patient was referred for outpatients follow-up, free from symptoms.

\section{Case 2}

SJSS, a 50-year-old female who had been healthy until 3 months previously, suffered a single episode of sudden, high intensity, postprandial pain in the epigastric area. Once pain had been managed using a nonsteroidal anti-inflammatory and intravenous tramadol, the patient was investigated further using angiotomography of the thoracoabdominal aorta, which showed that the celiac trunk had undergone traumatic dissection due to extrinsic pressure exerted by the median arcuate ligament of the diaphragm (Figure 2) and revealed thrombosis of the common hepatic artery with a chronic appearance (Figure 3 ). The patient was referred for outpatients follow-up.

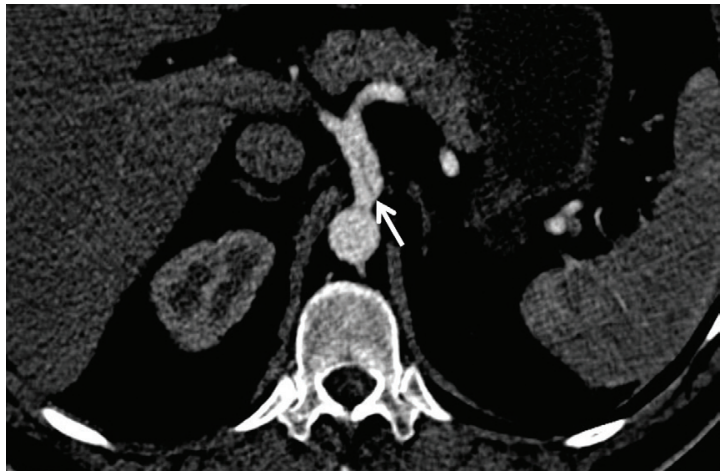

Figure 1. Axial angiotomography image showing failure of linear filling compatible with a dissection flap (arrow) of the celiac trunk, which is mildly dilated.

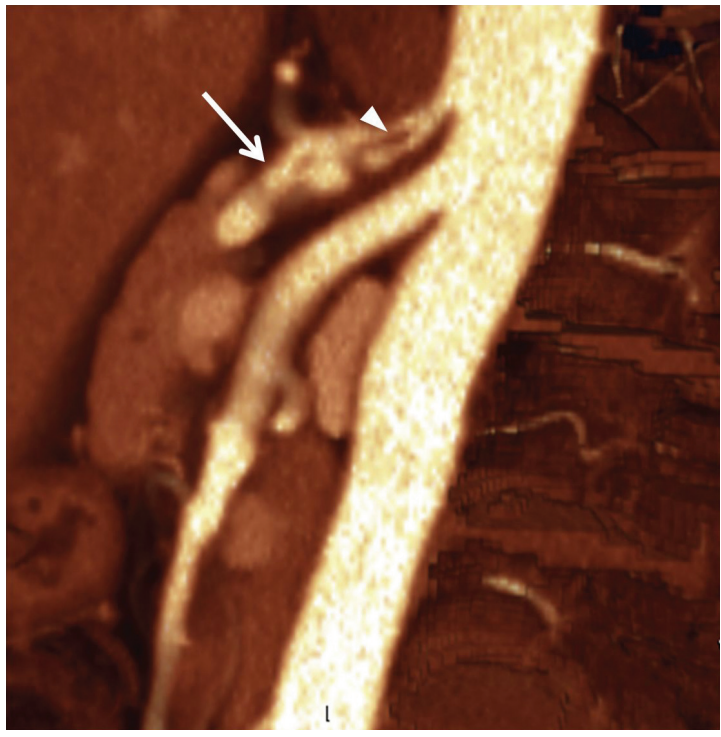

Figure 2. Angiotomography with maximum intensity projection reconstruction in the sagittal plane showing an elongated failure to fill the celiac trunk interior (arrowhead) corresponding to the dissection flap. There is mild compensatory dilation downstream (arrow).

\section{Case 3}

MTML, a 48-year-old hitherto healthy female patient, developed a condition involving sudden epigastric pain with onset $48 \mathrm{~h}$ previously. Abdominal ultrasonography conducted in the emergency room was normal. Since the patient had a history of atopic disease, the investigation was continued using magnetic resonance angiography, which showed a dissection flap in the celiac trunk (Figure 4). After clinical treatment of the initial symptoms, the decision was taken to opt for conservative management.

\section{DISCUSSION}

Arterial dissection is defined as separation of the artery wall by an intramural hematoma between the 


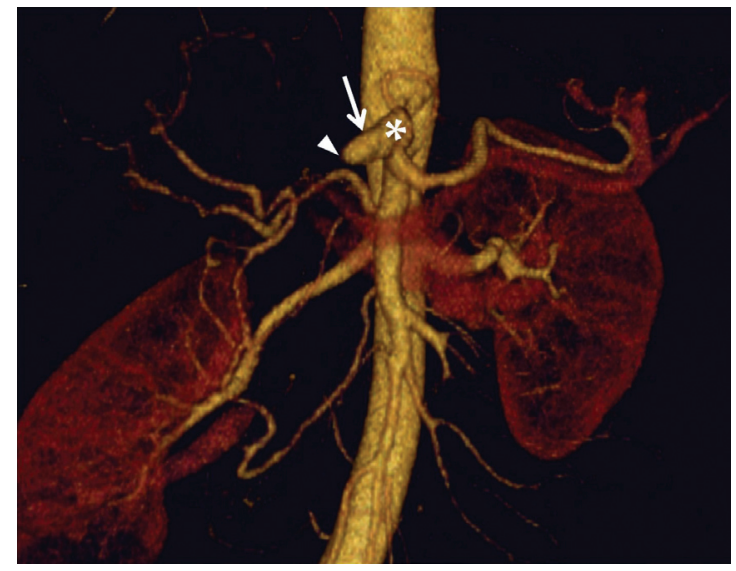

Figure 3. Angiotomography with volume rendering reconstruction showing the celiac trunk $\left({ }^{*}\right)$, the common hepatic artery (arrow) and an abrupt interruption in flow (arrowhead) compatible with obstruction by post-dissection thrombosis.

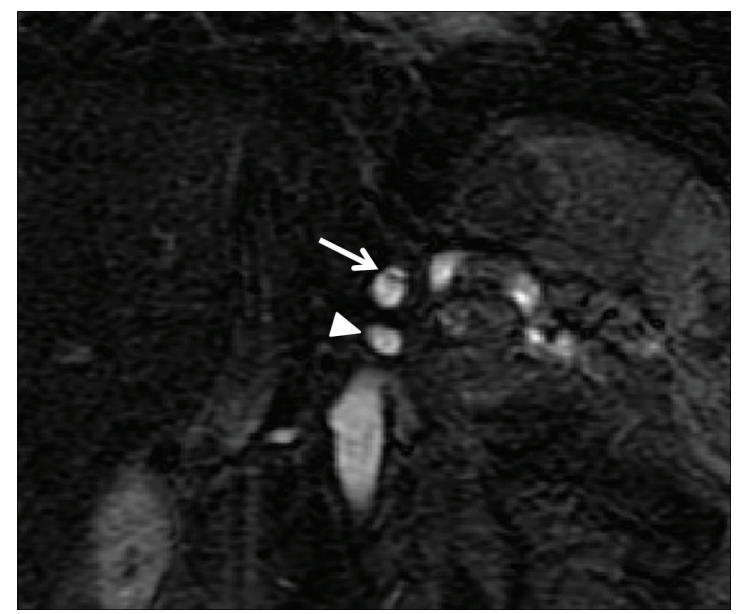

Figure 4. T1-weighted coronal magnetic resonance angiography image with contrast showing a failure of linear filling compatible with a dissection flap (arrow) in the celiac trunk. The superior mesenteric artery (arrow head) remains pervious with no signs of dissection.

two elastic layers. ${ }^{1,5,6}$ Spontaneous arterial dissection is more common among men (at a proportion of five men to each woman) and the mean age of patients is approximately 55 years. ${ }^{3}$ Arterial dissection is described as isolated when there is no related aortic dissection and is more often observed in the renal and carotid arteries, but rarely seen in visceral arteries. ${ }^{4,5}$ The most common types of extra-aortic dissection, in descending order of frequency, are: renal artery, coronary artery, cerebral artery, carotid artery, vertebral artery and visceral artery dissections. ${ }^{5}$ Spontaneous dissection of the visceral arteries was first described by Baurersfeld in 1947 and is an extremely uncommon condition. ${ }^{2}$ Spontaneous dissection of the renal artery has been reported more often in the literature than dissection of the celiac artery. ${ }^{2}$ Only 55 cases of spontaneous dissection of visceral arteries had been reported up to $2007 .{ }^{3}$ Of these, just 11 cases of spontaneous dissection of the celiac trunk had been reported since $1959 .^{3}$

Isolated spontaneous dissection of the celiac trunk is a rare entity. The majority of these cases have been observed in young patients and were managed using surgery or conservative treatment. Histology has shown that dissection occurs between the internal and the external elastic lamina, in contrast with dissection of the aorta, where the cleavage plane runs between the first and second parts of the tunica intima. ${ }^{2}$

Conditions that have been identified as causing arterial dissection include arterial hypertension, atherosclerosis, trauma, iatrogeny, pregnancy, syphilis, polyarteritis nodosa, fibromuscular dysplasia, cystic degeneration of the media (Marfan Syndrome) and other congenital disorders of vessel walls (Ehlers-Danlos Syndrome, for example). ${ }^{5,7}$ Other precipitating events can include mechanical stretching and microtraumas caused by effort or by rapid increases in intra-abdominal pressure, such as, for example, sneezing or standing up. However, in the majority of cases of isolated spontaneous dissection of the celiac trunk the cause remains unknown. ${ }^{3}$

Although rare, isolated dissection of visceral arteries has historically conferred poor prognosis. To date, the natural history of the disease is unpredictable and prognosis is dependent on the degree of compromise of subsegmental branches. Acute signs of hepatic ischemia or hemorrhage are indicative of poor prognosis. ${ }^{3}$

The most common initial clinical manifestation is sudden abdominal pain in the epigastric area. ${ }^{3}$ Clinical diagnosis is difficult because symptoms are relatively nonspecific and overlap with other conditions; making a high degree of clinical suspicion necessary. Some authors have suggested that a triad comprising sudden epigastric pain, weight loss and an epigastric systolic murmur is pathognomonic of this clinical condition. ${ }^{4,6}$

Despite the reports that the majority of patients suffer abdominal pain, there is often a discrepancy between the symptoms reported and the signs detected during physical examination, with the first being more intense than the second. Chronic dissection of the celiac artery can manifest with symptoms of postprandial abdominal pains and weight loss. ${ }^{2}$ In rare cases, dissection of the celiac trunk can also manifest as obstructive jaundice or pancreatitis. ${ }^{1,3}$ 
The nonspecific symptoms and clinical signs and the need to confirm the hypothesis of dissection, determine its extension or even identify other pathological conditions mean that diagnosis is generally established using imaging exams. Invasive angiography has traditionally been considered the gold standard examination for diagnosis, but recently computed tomography $(\mathrm{CT})$ has acquired increasing importance. ${ }^{3,4,8,9}$ As more advanced CT equipment has been developed along with image acquisition techniques that allow high-quality twodimensional and three-dimensional reconstructions, CT with injection-pump administration of contrast, or angiotomography, has become one of the most useful diagnostic techniques for investigating visceral artery dissections and providing details on the path of the dissection and its propagation into arterial system branches. ${ }^{4,5}$ Furthermore, angiotomography offers the possibility of comparing measurements of the extent of involvement with high reproducibility and accuracy for followup. ${ }^{5,8}$ Several different studies have suggested that angiotomography is a precise method for diagnosis and serial follow-up images of arterial dissection that is less invasive than angiography. ${ }^{5,8,10}$ In support of this position, recent research has shown that angiotomographic diagnosis and follow-up is associated with a significant reduction in morbidity compared with angiography. ${ }^{3,4,8,10}$ In view of this, angiotomography is now considered the first choice imaging exam for diagnosis of celiac trunk dissection, although magnetic resonance angiography, Doppler ultrasonography and conventional angiography can also be used. ${ }^{2,10}$

Dissection of the celiac trunk can occur with concomitant formation of an arterial aneurysm. ${ }^{3,5,9}$ Kim et al. state that intimal delamination in angiotomographic images is a pathognomonic diagnostic finding, while observation of an eccentric mural thrombus in the artery lumen should raise a suspicion of dissection. ${ }^{2,11}$ Observation of a mural thrombus may be the only clue to the existence of a dissection since intimal delamination is not always visible. ${ }^{2,3,5,11}$ In such circumstances, misdiagnosis of a dissection as a thromboembolic occlusion may lead to unnecessary prescription of pharmacological thrombolysis. ${ }^{2,3,5,11}$ Silvestre et al. described a case of simultaneous aneurysm and dissection of the celiac trunk in which the dissection was identified on angiotomography as a failure of linear filling compatible with a laminar dissection. ${ }^{12}$ Spontaneous dissection cases may also exhibit densification of the fat planes surrounding the celiac trunk on tomography. This finding may be predictive of a predisposition for the dissection to extend to adjacent vessels. $^{3}$

The ideal treatment for dissection of the celiac artery is still a controversial subject, in part because of the condition's rarity, but also because treatment options are dependent on the patient's hemodynamic status, on involvement of other vessels, on response to conservative treatment and on development of complications. ${ }^{5}$ A range of vascular complications have been described, such as propagation of the dissection to adjacent vessels causing visceral infarcts and development of aneurysms. The cause of this aneurysm formation is not yet clear, but it may reflect an individual genetic predisposition to weakening of the artery wall, vascular rupture and mesenteric ischemia. ${ }^{3}$

Where patients are hemodynamically stable, conservative management has generally been attempted. The objectives of conservative clinical treatment do not only include preventing progression of the dissection by controlling arterial blood pressure, but also extend to avoiding thromboembolic complications through administration of anticoagulants. ${ }^{3,4,8}$ In view of this, 3 to 6 months' treatment with anticoagulant agents or antiplatelet drugs, aiming for a target international normalized ratio (INR) of 2.0 to 3.0, in combination with strict control of arterial blood pressure ${ }^{5,7}$ have been recommended for prevention of thromboembolic complications. Administration of an anticoagulant immediately after diagnosis induces healing of the dissection and dissolution of the mural hematoma while preventing thromboembolic complications. ${ }^{5,8}$ Additionally, secondary antiplatelet treatment is recommended to prevent thrombosis in patients who have stenotic lesions. ${ }^{2}$ Conservative treatment may also include antihypertensive and antiinflammatory drugs and corticosteroids in addition to the anticoagulants. ${ }^{2,3}$

Surgical or endovascular interventions should be considered in the following situations: when the patient is hemodynamically unstable or has persistent abdominal pain, when conservative medical treatment fails to control arterial blood pressure and when the dissection is progressing further. ${ }^{2,3,7}$ This can be investigated through serial follow-up using imaging methods, but to date there is no established consensus on the frequency with which these examinations should be conducted. ${ }^{2}$ If angiotomography shows active contrast leakage from the celiac trunk, emergency laparotomy is the treatment of choice. ${ }^{3,4,8}$ Sadly, even when immediate 
surgical management is attempted, patients with active hemorrhaging have an estimated mortality of $50 \%{ }^{4}$

Surgical treatment of celiac trunk dissection is performed to prevent acute complications, such as rupture of an aneurysm or mesenteric ischemia, or to prevent chronic complications such as stenosis. Surgical treatment options include resection of the dissected segment with anastomosis or construction of a bypass. Surgery also provides an opportunity to biopsy the dissected artery, which may be necessary in order to exclude vasculitis as a cause of dissection. ${ }^{2,10}$

Endovascular treatment of celiac trunk dissection has only been reported rarely, although endovascular stent placement has been described for cases of spontaneous superior mesenteric artery dissection. ${ }^{2}$

There are not yet any consistent data on the difference in long-term results of patients treated surgically or with conservative drug-based treatment, because of the scarcity of reports in the literature. ${ }^{4}$

\section{CONCLUSIONS}

Although spontaneous dissection of the celiac trunk is uncommon, it should be included as a differential diagnosis hypothesis when patients present with acute epigastric abdominal pains. Advances in both equipment and techniques have led to angiotomography becoming the imaging exam of choice for confirming a diagnosis of dissection, for monitoring the condition and for planning interventions. A failure of linear filling of the lumen of the vessel under observation may offer a direct sign of dissection, but indirect signs should also be sought. The ideal treatment is not yet wellestablished, but can include conservative approaches, surgical intervention or endovascular treatment. Data provided by angiotomography can offer an additional foundation from which surgeons can determine the therapeutic management method.

\section{REFERENCES}

1. Galastri FL, Nasser F, Affonso BB, Amorim JE, Travassos FB. Dissecção espontânea do tronco celíaco: Qual a melhor abordagem terapêutica? J Vasc Bras. 2013;12:68-74. http://dx.doi. org/10.1590/S1677-54492013000100014

2. Vaidya S, Dighe M. Spontaneous celiac artery dissection and its management. J Radiol Case Rep. 2010;4(4):30-5. PMCid:PMC3303389. http://dx.doi.org/10.3941/jrcr.v4i4.408

3. D'Ambrosio N, Friedman B, Siegel D, Katz D, Newatia A, Hines J. Spontaneous isolated dissection of the celiac artery: CT findings in adults. AJR Am J Roentgenol. 2007;188:W506-11. PMid:17515339. http://dx.doi.org/10.2214/AJR.06.0315

4. Ashurst J, Myers P, Evans E. Spontaneous Celiac Artery Dissection: A Rare cause of Abdominal Pain. In: Foundation of Osteopathic Emergency Medicine Competition. Las Vegas, Oct, 2011.
5. Liao CY, Chen CB, Hsia CH, Liv CK, Yang AD. Isolated Spontaneous Dissection of the Celiac Artery with Aneurysm Formation.J Radio Sci. 2012;37:159-62.

6. Chaillou P, Moussu P, Noel SF, et al. Spontaneous dissection of the celiac artery. Ann Vasc Chir. 1997;11:413-5. http://dx.doi. org/10.1007/s100169900070

7. Fenoglio L, Allione A, Scalabrino E, et al. Spontaneous dissection of the celiac artery: a pitfall in the diagnosis of acute abdominal pain. Presentation of two cases. Dig Dis Sci. 2004;49:1223-7. PMid:15387350. http://dx.doi. org/10.1023/B:DDAS.0000037816.57229.6f

8. Poylin V, Hile C, Campbell D. Medical management of spontaneous celiac artery dissection: A case report and a review of the literature. Vasc Endovascular Surg. 2008;42:62-4. PMid:18238870. http://dx.doi.org/10.1177/1538574407305462

9. Matsuo R, Ohta Y, Ohya Y, et al. Isolated dissection of the celiac artery-a case report. Angiology. 2000;51:603-7. PMid:10917586. http://dx.doi.org/10.1177/000331970005100710

10. Glehen $O$, Feugier P, Aleksic Y, Delannoy P, Chevalier JM Spontaneous dissection of the celiac artery. Ann Vasc Surg. 2001;15:687-92. PMid:11769152. http://dx.doi.org/10.1007/ s10016-001-0012-0

11. Kim JH, Roh BS, Lee YH, Choi SS, So BJ. Isolated spontaneous dissection of the superior mesenteric artery: percutaneous stent placement in two patients. Korean J Radiol. 2004;5:134-8 PMid:15235239. http://dx.doi.org/10.3348/kjr.2004.5.2.134

12. Silvestre JMS, Sardinha WE, Piazzalunga M, Fernandes B, Motta F, Silvestre GS. Dissecção isolada do tronco celíaco: relato de caso. J Vasc Bras. 2010;9:152-5. http://dx.doi.org/10.1590/ S1677-54492010000300010

Correspondence Ernesto Lima Araújo Melo Universidade Estadual do Ceará - UECE Centro de Ciências da Saúde Curso de Medicina

Av. Paranjana, 1700 - Campus do Itaper CEP 60740-000 - Fortaleza (CE), Brazil E-mail: ernesto.melo@uece.br

Author information

ELAM é professor adjunto da disciplina de Diagnóstico por Imagem do Curso de Medicina da Universidade Estadual do Ceará (UECE) doutor em radiologia pela Universidade de São Paulo (USP), médico radiologista do Centro de Imagens do Hospital Geral César Cals (HGCC) e da Clínica Boghos Boyadjian. RAS e FTMP são graduandos do Curso de Medicina da Universidade Estadual do Ceará (UECE)

Author contributions Conception and design: ELAM, RAS, FTMP Analysis and interpretation: ELAM, RAS, FTMP

Data collection: ELAM Writing the article: ELAM, RAS, FTMP Critical revision of the article: ELAM, RAS, FTMP Final approval of the article*: ELAM, RAS, FTMP Statistical analysis: N/A Overall responsibility: ELAM Financial support: None.

* All authors have read and approved of the final version of the article submitted to J Vasc Bras. 